\title{
Cloning and bioactivity analysis of a CXC ligand in black seabream Acanthopagrus schlegeli: the evolutionary clues of ELR+CXC chemokines
}

\author{
Cai Zhonghua*1, Gao Chunpin ${ }^{1}$, Zhang Yong1, Xing Kezhi² and \\ Zhang Yaou*1
}

Address: ${ }^{1}$ Life Science Division, Graduate School at Shenzhen, Tsinghua University, Shenzhen, PR China and ${ }^{2}$ Tianjin Key Lab of Aqua-ecology and Aquaculture, Tianjin Agricultural University, Tianjin, PR China

Email: Cai Zhonghua* - caizh@sz.tsinghua.edu.cn; Gao Chunpin - gaocp@sz.tsinghua.edu.cn; Zhang Yong - zhangy@sz.tsinghua.edu.cn; Xing Kezhi - kjc@tjau.edu.cn; Zhang Yaou* - zhangyo@sz.tsinghua.edu.cn

* Corresponding authors

This is an Open Access article distributed under the terms of the Creative Commons Attribution License (http://creativecommons.org/licenses/by/2.0), which permits unrestricted use, distribution, and reproduction in any medium, provided the original work is properly cited.

\begin{abstract}
Background: The $\mathrm{ELR}^{+} \mathrm{CXC}$ chemokines are multifunctional mediators that are mainly responsible for the recruitment of leucocytes to sites of inflammation and infection. Because of their high sequence identity with mammalian IL-8, fish IL-8-like CXCs have been named as piscine 'IL-8' and included in the ELR+ subgroup, even though there is no reliable functional or evolutionary evidence to support this classification.
\end{abstract}

Results: In this investigation, a homologue of piscine 'IL-8' from black seabream (Acanthopagrus schlegeli), called BS CXC, has been cloned and analyzed. The results revealed that BS CXC has a high gene similarity and tertiary structure similarity with piscine and mammalian $C X C$ chemokines, both ELR-CXC and ELR ${ }^{+} C X C$, although it has a lower identity with ELR-CXC, compared with $E L R^{+} C X C$ chemokines. Like other piscine IL-8, BS CXC has only an incomplete ELR motif, which is essential for the mammalian $E L R^{+} C X C$ ability to attract granulocytes. Bioactivity assay demonstrated that the BS $\mathrm{CCXC}$ produced in $E$. coli significantly stimulated migration of fish neutrophils and macrophages, but had no effect on rat neutrophils and macrophages, whereas hrlL8 induced strong chemotaxis of fish neutrophils but did not affect fish macrophages. BS CXC seems show some structural and functional properties of the intermediate between ELR-CXC and $\mathrm{ELR}^{+} \mathrm{CXC}$.

Conclusion: As an incomplete ELR ${ }^{+} \mathrm{CXC}$ chemokine from a modern fish, BS CXC provides some clues on the evolution from ancient ELR-CXC to ELR+CXC by retaining some properties of the intermediate stage in evolution, and it may be more appropriate to call this molecule 'piscine CXC with an incomplete ELR', instead of terming it fish 'IL-8'.

\section{Background}

Chemokines are a group of small peptide chemotactic cytokines, which are multifunctional mediators that can trigger inflammatory cell chemotaxis toward a site of infection and injury by binding to a G-protein-coupled cell surface receptor $[1,2]$. Chemokines have pleiotropic 
effects in regulating immunity and angiogenesis, and stem cell trafficking appears to play a central role in linking innate and acquired immune regulation $[3,4]$. Functionally, chemokines fall into two main categories; one is homeostatic and generally involved in lymphocyte trafficking, immune surveillance and localization of lymphocytes; the other category is only produced by cells during inflammation to prompt the migration of leukocytes to an injured or infected site and also activates cells to raise an immune response and commence the wound healing process. [5]. Based on structural properties and primary amino acid sequence, chemokines are divided into four groups, including the CXC, CC, $\mathrm{C}$ and CXXXC subfamily, according to the position of the first two cysteines [6,7]. Nearly 50 different CXC and CC chemokines have been identified and well studied in human and mammalian cells by biochemical purification or cDNAdeduced amino acid sequencing $[5,8]$.

CXC chemokines can be further subdivided into those that contain a short sequence of Glu-Leu-Arg (the ELR motif) and those that do not, the ELR+ subgroup and the ELR' subgroup $[9,10]$. The ELR ${ }^{+} \mathrm{CXC}$ specifically recruits polymorphonuclear leucocytes (PMN) into inflamed tissues and promotes angiogenesis by specifically binding to CXCR1 and/or CXCR2 [10], whilst ELR-CXC specifically attracts lymphocytes and monocytes, with poor chemotactic ability for neutrophils, and inhibits angiogenesis $[3,5,9]$.

In recent years, the progress of nonmammalian chemokine research has been rapid since the first 'IL-8' homologue was cloned in lamprey [11]. Although many gene products are identified by the molecular cloning approach [12-19], little information is available on their biological effects. Because of their high sequence identity with mammalian IL-8, fish IL-8-like CXCs have been named as piscine 'IL-8' and included in the $\mathrm{ELR}^{+}$subgroup, even though there is no reliable functional or evolutionary evidence to support this classification. In this paper, we cloned a homologue of piscine 'IL-8' from black seabream (Acanthopagrus schlegeli), called BS CXC, and analyzed its sequence and bioactivities. Finally, we used the BS CXC as a model to evaluate the position of piscine 'IL-8' in the evolutionary development of chemokines. This investigation thus provided some insights into the evolution of chemokines.

\section{Results}

\section{Cloning and sequence analysis of the BS IL-8-like gene}

A 175 bp sequence was cloned by PCR using a pair of degenerated primers designed from the conserved region of the mammalian and piscine CXC sequence and the sequence showing relatively higher identity and similarity with the known mammalian and piscine CXC ligands (E $<\mathrm{e}^{-10}$ ). Subsequently, two specific primers of IL-8F85 and IL-8R94 were designed to get the $3^{\prime}$ and $5^{\prime}$ ends of BS CXC cDNA, respectively. The products of $360 \mathrm{bp}$ and $492 \mathrm{bp}$ were amplified by RACE. Compiling the three overlapped sequences gave a consensus sequence of $851 \mathrm{bp}$, which represents the full coding sequence of BS CXC cDNA (Fig. 1 ), then, we designed the other pair of primers, $\mathrm{gF}$ and $\mathrm{gR}$ which covers the full ORF coding sequence region of the candidate BS CXC to get the full length transcript of BS CXC with RT-PCR. The product of RT-PCR was sequenced and the full length transcript of BS CXC was confirmed.

The BS CXC sequence contains an 83 bp 5 ' untranslated region (UTR) and a 285 bp open reading frame (ORF) encoding a propeptide of 95 amino acids, including a signal peptide of 22 amino acids. The deduced peptide has a putative molecular weight (MW) of $10.5 \mathrm{kDa}$, a theoretical isoelectric point of 7.86, and a 380 bp 3' UTR, which contains three RNA unstable motifs (ATTTA) and a typical polyadenylation signal $18 \mathrm{bp}$ upstream of the poly A tails. The sequence was deposited in Genbank with the accession No. of DQ000611.

The putative peptide of BS CXC contains a typical structure of the chemokine CXC ligand, which is formed by two cysteines separated by Arg. The four cysteines that should be involved in forming a disulphide bridge are highly conserved, and the CXC chemokine family signature of C-x-C- [LIVM]-x(5,6)- [LIVMFY]-x(1,2)- [RKSEQ] $\mathrm{x}$ - [LIVM]-x(2)- [LIVM]-x(5)- [STAG]-x(2)-C-x(3)- [EQ][LIVM] (2)-x(9,10)-C-L- [DN] [20] was identified in BS CXC (Fig. 2A). The multiple alignments of fish and other animal CXC peptides also indicate that most of the conserved amino acids are found in the mature peptide region, especially in the signature, forming secondary structure regions. The tertiary structure predicted by the SWISS-MODEL shows that the BS CXC had a similar structure to piscine and mammalian CXC chemokines, both ELR ${ }^{+} \mathrm{CXC}$ and ELR-CXC, which contains three $\beta$ strands in the $\mathrm{N}$ terminal and a $\alpha$ helix in the $\mathrm{C}$ terminal, and this is in common with the results of human CXC X-rays [21-24] (Fig. 2B).

Structural analysis uncovered significant differences in receptor binding regions; like other piscine 'IL-8', the BS CXC putative peptide lacks a complete ELR motif, which is important for its chemotaxis of the neutrophils, because the motif is the essential domain in the $\mathrm{ELR}^{+} \mathrm{CXC}$ ligand binding to the receptor [25]. BS CXC and all the other fish 'IL-8' only have an incomplete ELR motif; for example, the Arg was substituted by His to be the ELH in BS CXC. For the DLR motif in rainbow trout, the Glu was replaced by Asp [12], for the SLH motif in flounder [17], the Glu and Arg were substituted by Ser and His, respectively. The 


\section{CAAACAGCAGAGCAAGAGTGCAGCTGAACAAAGAAAGGAAAAGCTGAGGAGAAAGGAAA}

61 CCAGGCAAAAGAAAAAAGCTGAAAGAGAAACATCGTCTTCTTTTCTTCATCAGACAACTT

121 GTCAACTCTCTGAAGGAAGTTCTTATTCTTTAGTGTTAATTGT TGCAGAGT TTGTAAAAG

181 GCACAATGATGAGCAGCAGAGTCTTCGTCGCCACTATTGTGGGGCTCCTGGCCTTCCTCG

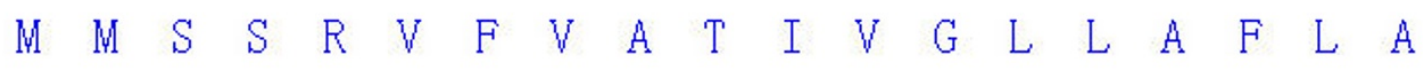

241 CCATCAGTGAAGCGAGCCTGGGAGTGGAGCTGCACTGCCGCTGCATCCAAACAGAGAGCA

$$
\text { I } S \text { E } A\left[\begin{array}{llllllllllllllllll}
S & L & G & V & E & L & H & C & R & C & I & Q & T & E & S & K \\
\hline
\end{array}\right.
$$

301 AACCGATCGGCCGCCACATTGAGAAGGTGGAGCTGATTCCTGCCAACTCCCACTGCGAGG

$$
\begin{array}{lllllllllllllllllllll}
P & I & G & R & H & I & E & K & V & E & L & I & P & A & N & S & H & C & E & E \\
\hline
\end{array}
$$

361 AGACCGAGATCATTGCCACTCTGAAGAGGACAGGCCAAGAGGTTTGCCTGGACCCCGAGG

$$
\begin{array}{llllllllllllllllllllllllll}
\mathrm{T} & \mathrm{E} & \mathrm{I} & \mathrm{I} & \mathrm{A} & \mathrm{T} & \mathrm{L} & \mathrm{K} & \mathrm{R} & \mathrm{T} & \mathrm{G} & \mathrm{Q} & \mathrm{E} & \mathrm{V} & \mathrm{C} & \mathrm{L} & \mathrm{D} & \mathrm{P} & \mathrm{E} & \mathrm{A}
\end{array}
$$

421 CTCCCTGGGTGAAGAAAGTGATTCAGAAGATCCTGTCCAACGCGAGACGTTGAGCAGACT

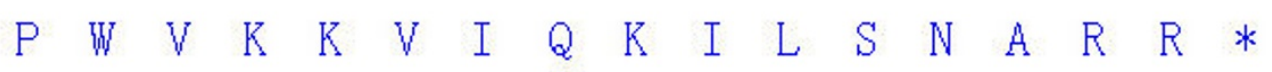

481 GGAAGAGATGTGCTTCATGAGTCCGAGCTGTTTACTGTATCGACCAAAGACAACCAAAGA

541 CCAAAAAGTGT TGA TGAGCTGATTTGATCT TGCTCATTTTTTAAAATGTCCTTATCATTT

601 GTTGAAAGTGACAAAAGATTTTATCTATTCAGAGTACGTTTGTATCAAACATATTATTTA

661 TTATAGTTATTAATATCATGTCTGTATGTCACGTATGTGTTTTACTGTTTCTTTAACTTA

721 TGTCTTTAACATATTTATTTCTGTATTTATGAGACATAAATGTATCTGGAATCTGGATTT

781 CAAGATCTGGCTCTGACAATCTGTTGTTTAATAAAAGAAGTACTATGAAATTGAAAAAA

\section{AAAAAAAAAAA}

\section{Figure I}

Sequence of BS CXC. The nucleotide sequences of BS CXC are represented by black letters and the deduced amino acid sequences by blue letters. The arrow indicates the signal peptide cut site; the CXC subfamily signature is in the box and the CXC motif is in the highlighted box; the RNA instability motif is underlined and the polyadenylation signal sequence is highlighted and underlined; the asterisk shows the stop code. Accession numbers of BS CXC is DQ0006II.

other piscine CXCs also have an incomplete ELR motif (Fig. 2A).

Alignment of amino acid sequences of the BS CXC with the other CXC chemokines indicates that the BS CXC has a higher similarity with all the CXC chemokines (36$72 \%)$, both ELR+CXC(72-42\%) and ELR-CXC(49-36\%), and has higher identity with ELR ${ }^{+}$CXC (60.5-25.9) but a lower identity with ELR-CXC(28.1-16.1\%) (Fig. 2A). The BS CXC has the highest identity with bony fish IL-8 (60.5-
$51 \%)$, then the cartilaginous banded dogfish Triakis scyllia (43.1\%) and mammalian ELR+CXC (25.9-40\%). But the Agnatha (jawless fishes) lamprey only has a lower identity (33.6-18.6\%) with all the CXC chemokines [17].

\section{Phylogenetic analysis}

A phylogenetic tree was constructed based on the mature peptide of BS CXC and part of the known CXC ligands by using the neighbour-joining algorithm (Fig. 3). The $\mathrm{ELR}^{+} \mathrm{CXC}$ of mammalian CXC and incomplete ELR ${ }^{+} \mathrm{CXC}$ 


\author{
A \\ lamprey \\ sharkXC18 \\ carpcxc \\ trout IL8 \\ flounderCXCL8 \\ BS CXC \\ catCXCL8 \\ dogIL8 \\ monkeyCXCL8 \\ chickenk60
}

lamprey sharkCXC18 carpcxc trout IL8 flounderCXCL8 BS CXC catCXCL8 dogIL8 monkeyCXCL8 chickenk60
-MTMNAKLLVVLLALALLGHSQAMSVFGGGIF--CQCVHV ISKFIHPKHFQTMEVIPQSS 56 -MNSKV ILAVLALFILYLASTQAASLRHAG SLICQCIKTNSKFIHPRRMENIE IFPSGP 59 -MHFK IFS-VIVFLGFLTIGEGMSLRGLGVDPRRCIETESQRIG-KLIESVELFPPSP 56 -MS IRMSASLVVVLLALLTITEGMSLRGMGADLICRCIETESRRIG-KLIKKVEMFPPSS 58 -MSSRV IVVAVMVLLASLAISE VSLRSLGVSLICRCIETESRPIG-RYIKSVEI ISPNS 58 -MSSRVFVATIVGLLAFLAISE ---SLGVELHCRCIQTESKPIG-RHIEKVELIPANS 55 -MTSKLVVALLAAFMLSAALCE AVLSRIS\$ELICQCIKTHSTPFNPKLIKELTVIDSGP 59 -MTSKLAVALLAAFVLSAALCE AVLSRVS\$ELICQCIKTHSTPFHPKYIKELRVIDSGP 59 -MTSKLAVALLAAFLLSAALCE AVLPRSAKELICLCIKTYSKPFHPKFIKELRVIESGP 59 -MMGKAVAAVMALLL ISMAGAKGMAQARSA ELLCQCIETHSKFIHPKFIQNVNLTPSGP 59$$
*
$$
:

CrCIqteskpIgRhIekVelipanS

NCKNVE I IVTMKSTNNQICLNPDAPWVRKV ISHILDGAQTPKSTQ------ 101

HCSNVEI IATLK-NGTPVCLNPEAAWVKKI IDMIIKNSEKTES-------- 101

HCKDTE I IATLKVSRKEICLDP IAPWVKKV IEK IIANKTPAA--------- 98

HCRDTE I IATLSKSGQEICLDVSAPWVKRV IEKMLANNK----_--_----- 97

HCDKTE I IATLKDTGVEICLDPEAPWVKRV INKLISKRRLSRWREMGSEAV 109

HCEETE I IATLKRTGQEVCLDPEAPWVKKV IQK ILSNARR----------- 95

HCENSE I IVKLV-NGKEVCLDPKQKWVQKVVEIFLKKAEKQNA-------- 101

HCENSE I IVKLF-NGNEVCLDPKEKWVQKVVQIFLKK-------------- 95

HCVNTE I IVKLS-DGRELCLDPKEPWVQRVVEKFLKRAESQNS-------- 101

HCKNVEVIATLK-DGREVLDPTAPWVKLI IKAILDKADTNNKTAS---- 104

$: * . *: . .: \quad: * *: \quad * *:::::$ :

hCeetEII atlkrtgqe vCLD

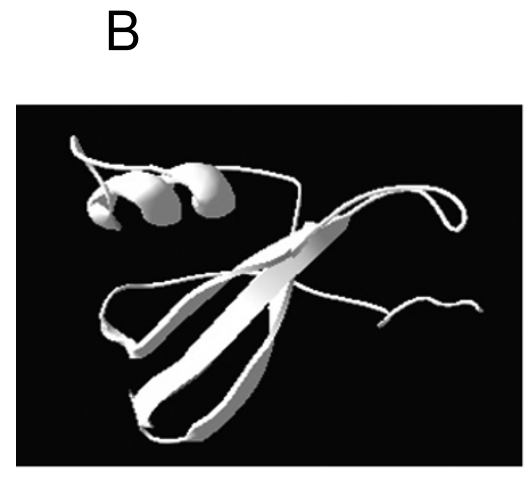

hulL8-1IKL

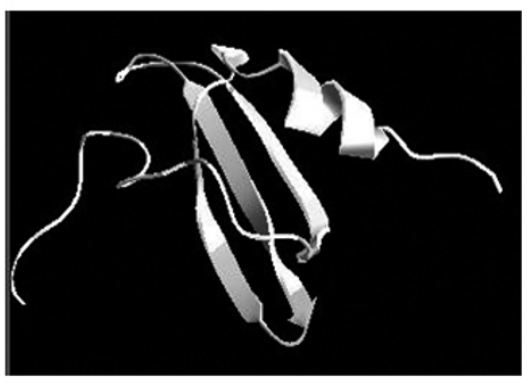

BS CXC

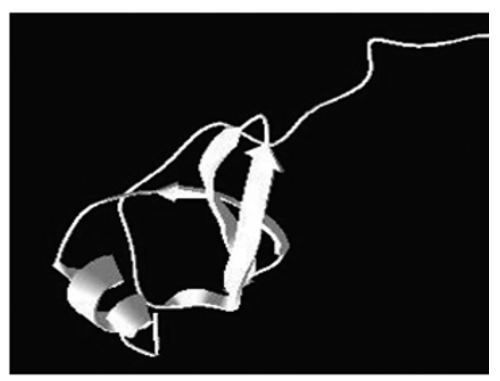

CXCL12(SDF-1)-1a15

Figure 2

Amino acid sequence alignment and Comparison of tertiary structure of BS CXC. A. Amino acid sequence alignment of BS CXC with other known CXCL8. The alignment was performed with the Clustal W program. Identical and similar sites are shown with asterisks $(*)$ and dots (. or :), respectively; the broken line indicates the signal peptide cut site. The conserved cysteines are highlighted, and the ELR motif associated with attracting neutrophils in mammals is in the box. B. Comparison of tertiary structure among the human IL-8 model pdb Ilkl (left), BS CXC (middle) and the CXCLI 2 (SDF-I) model pdb IaI5. The BS CXC models were predicted by the SWISS-MODEL and Swiss-PdbView software. 


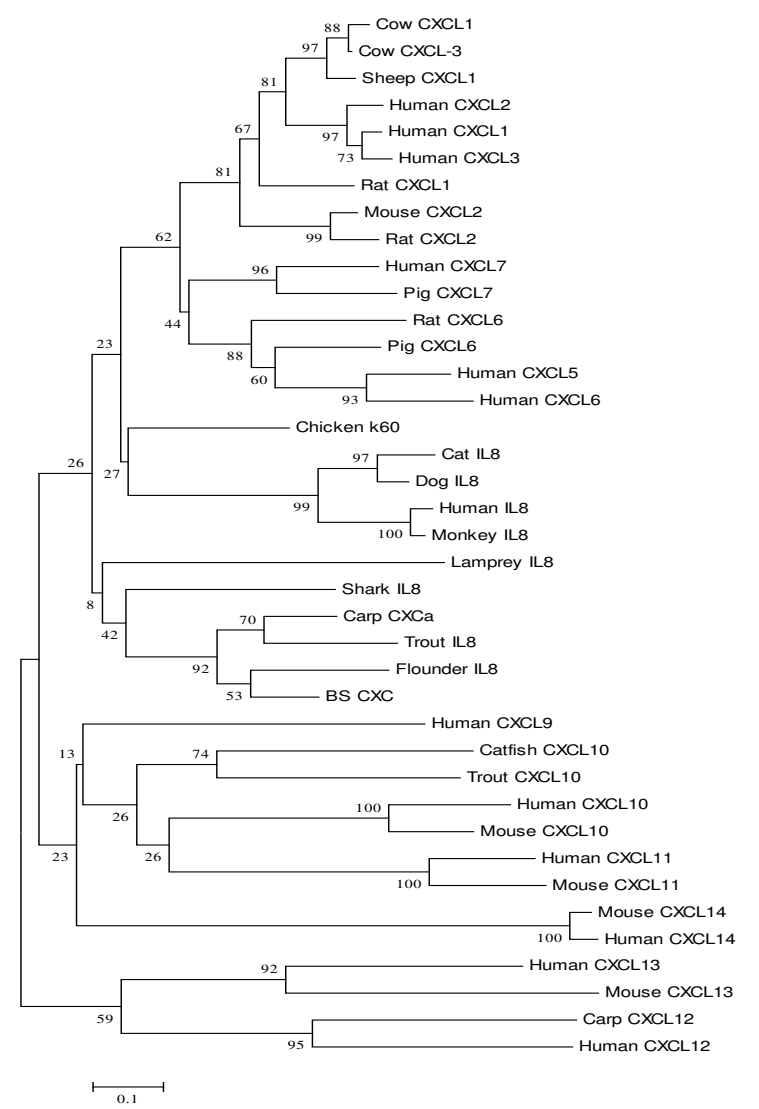

\section{Figure 3}

Phylogenetic analysis. The sequences were aligned by the CLUSTAL W program and the phylogenetic tree was constructed by neighbor-joining methods using MEGA version 2.I. The phylogenetic tree shows the relationship among the full-length amino acid sequences of the BS CXC mature peptide with other representative CXC sequences, Numbers at branch nodes represent the confidence level of 1000 bootstrap replications. The used sequences are represented as follows: human $C X C L I$ AAP36752; human CXCL3 NP_00208I; human CXCL4_P02776; human CXCL5 NP_002985; human CXCL6 NP_002984; human CXCL7 NP_002695; human IL-8 NP_000575; human CXCLI I OI4625; human CXCLI2_P4806I; human CXCLI3_O43927; human CXCLI4 O957I5; chicken K60_CAA752I2; Triakis scyllium IL-8 BAB79448; trout IL-8 CAC33585; lamprey IL-8 CAA I 3 I 4; flounder IL-8 AAL05442; carp CXCa CADI3 I89; BS CXC AAYI8807; cow CXCLI NP_78363 I; cow CXCL3 NP_776724; sheep CXCLI AAB93930; mouse CXCI 2 NP_033 I66; rat CXCLI NP_I I0472; Rat CXCL2 NP_446099; pig CXCL7 AAB28904; carp CXCLI2 CAD59916; catfish CXCLIO AAQ0I585; trout CXCLI0 CAD0II4I; rat CXCL3 BAA02009; rat CXCL6 NP_07I550; dog IL-8 JN084I; monkey IL-8 AAA86705; mouse CXCLI0 PI75I5; mouse CXCLII Q9JHH5; mouse CXCLI3 O55038; mouse CXCLI4 Q9WUQ6).

of piscine $\mathrm{CXC}$, which are orthologous genes that represent independent lineages and have diverged from ELR$\mathrm{CXC}$, share sister-taxon relationships on the evolutionary tree. All the piscine incomplete $\mathrm{ELR}^{+} \mathrm{CXC}$ chemokines formed one clade. In this clade, lamprey CXC of the Agnatha (jawless fishes) is in an independent branch that evolved first from ancestral CXC and later from cartilaginous fish CXC and other bony fish CXC. In the mammalian ELR ${ }^{+} \mathrm{CXC}$ clade, the orthologous genes of IL- 8 and chicken K60 ligands share parallel evolutionary relation- ships, with the orthologous genes of CXC 5-7 and CXC 13 forming sister branches. Piscine incomplete ELR $+\mathrm{CXC}$ chemokines originated almost contemporaneously through a series of gene duplication events. There is no solid evidence to confirm that fish incomplete CXC were clearly orthologous with mammalian IL-8. The results indicate that the ELR $+\mathrm{CXC}$ chemokine ligands may have evolved from ancestral ELR-CXC and diverged further during evolution to perform a special function. Fish incomplete $E L R+C X C$ retain some properties of the intermediate 
stage during the evolutionary development of highly specific CXC chemokines.

\section{Expression of natural and recombinant BS CXC}

Fluorescent real-time quantitative PCR was employed to measure the expression of the BS CXC transcript in the tissues of normal and challenged black seabream (Acanthopagrus schlegeli). The results showed basal expression of BS CXC in various organs, including the heart, gill, spleen, kidney and $\mathrm{HK}$, and the basal expression was higher in the blood than in other tissues (Fig. 4A). Figure 4A also demonstrated that poly(I:C) and LPS can significantly up-regulate BS CXC transcript expression in various organs. Twenty-four hours after stimulation with poly(I:C) and LPS, more than 4-fold up-regulation of BS CXC transcript expression was detected in the HK and spleen tissue and more than 2-fold transcript expression was detected in the kidney, gill and other tissues. LPS seems to have a stronger effect than poly(I:C) in the up-regulation of BS CXC expression. The results demonstrate that BS CXC expression can be induced by poly(I:C) or LPS, as in the case of other chemokines and cytokines [14].
To get purified recombinant protein for the functional assay of BS CXC, we generated a BS CXC expression construct through inserting a BS CXC mature peptide coding sequence into vector $\mathrm{PQE30}$ (Qiagen). The construct was transformed into E. coli M15 cells and the cells were induced to produce the recombinant BS CXC containing a 6 His tag at the N-terminus for purification. Figure 4B shows that the recombinant protein significantly increased before (lane 2) and after induction (lane 1). The molecular size of the recombinant protein is about 9.2 $\mathrm{kD}$, matching well with the predicted molecular mass weight. Lanes 3 and 4 show the purified protein. The BS rCXC protein was confirmed by Western blot analysis using an $\mathrm{mAb}$ against the histidine tag, in which a single band was detected (Fig. 4C).

\section{Chemotactic response of leucocytes towards the BS CXC gene}

According to the sequence analysis, $\mathrm{BS}$ CXC is a putative CXC chemokine with an incomplete ELR, so the chemokine might have the functional characters of both $\mathrm{ELR}^{+} \mathrm{CXC}$ and ELR-CXC. A migratory assay of leukocytes was performed to test our hypothesis. The neutrophils were collected from peripheral blood and macrophages were
A

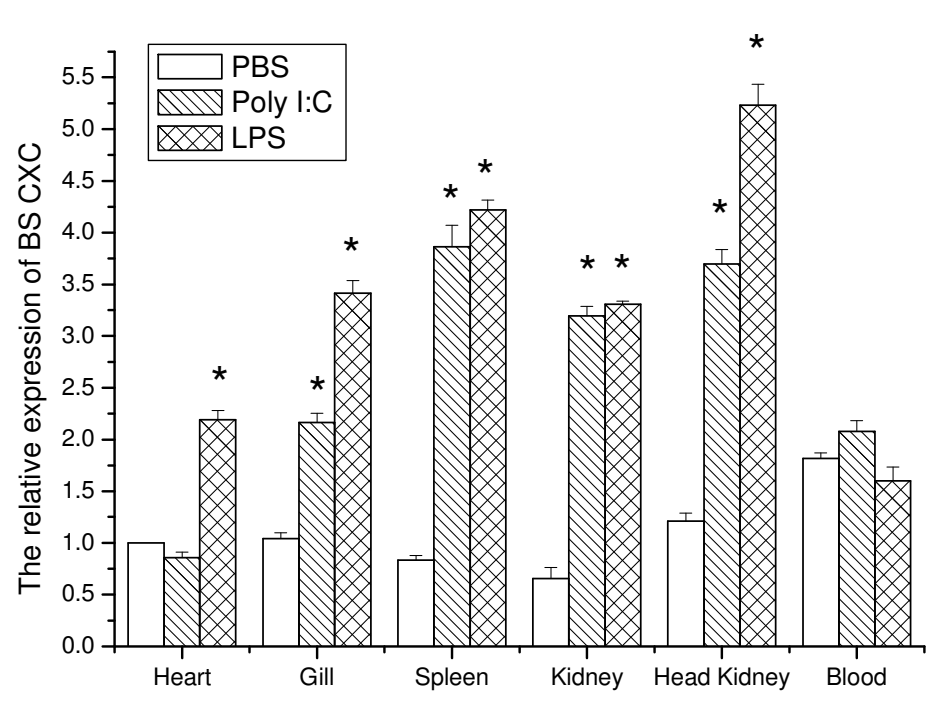

B

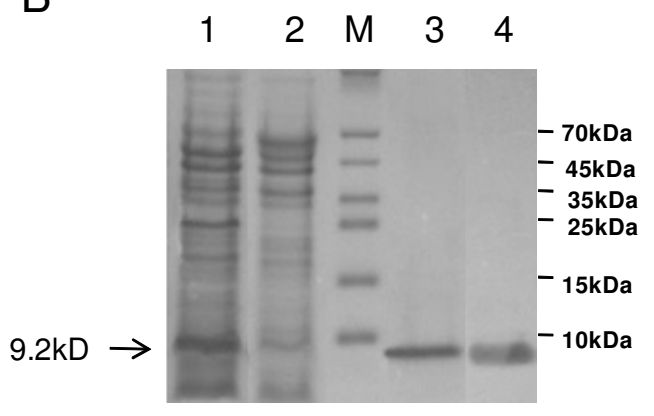

C

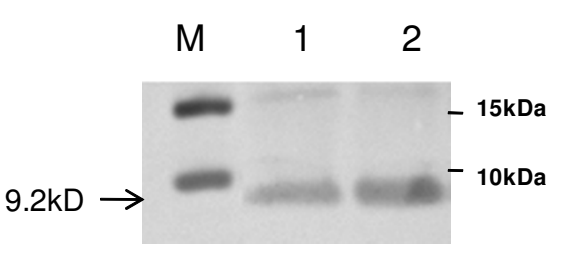

\section{Figure 4}

Expression analysis of the BS CXC. (A) The expression of BSCXC mRNA relative to b-actin analyzed by real-time PCR in Black Seabream after Polyl:C and LPS challenge. The values are shown as means \pm S.E., $n=3$. Significant differences between challenged group and control group are indicated by an asterisk $(P<0.01)$. (B) The plasmid BS CXC-pQE30 was transformed into E. coli MI 5 cells and induced by ITPG. Bacterial lysates (lane I) or purified BS rCXC (lanes 3 and 4) were separated on SDS-PAGE and stained by Coomassie brilliant blue R250. Lysate from uninduced cells was used as a control (lane 2). (C) The identity of the BS rCXC was confirmed by Western blotting using the antibody of $6 \mathrm{His}$. Lanes I and 2 showed BS rCXC. 
isolated from the lungs of rats and the head kidneys of black seabream and common carp. Dose-dependent chemotactic responses induced by BS CXC were observed in the migratory assays of $\mathrm{BS}$ neutrophils and macrophages (Fig. 5A and 5B). The chemotactic activity appeared at low doses of BS $\mathrm{rCXC}(10 \mathrm{ng} / \mathrm{ml})$, then became stronger with increasing doses of $\mathrm{BS} \mathrm{rCXC}$, and peaked at doses of $100 \mathrm{ng} / \mathrm{ml}$ for induction of neutrophils and $200 \mathrm{ng} / \mathrm{ml}$ for macrophages. The BS rCXC showed stronger chemotactic activity to BS neutrophils than to BS macrophages. This chemokine can also induce migration of carp neutrophils and macrophages, though its chemotactic activity to carp leucocytes was significantly lower than that to those of black seabream. However, neutrophils from higher vertebrates, such as the rat, did not show any chemotactic responses to BS rCXC. Our results suggest that $\mathrm{BS}$ rCXC can induce chemotactic responses in both neutrophils and macrophages of fish, but not mammalian, cells.

Piscine CXC could not induce mammalian cells, but we did not know whether mammalian CXC could affect fish cells or not. Human recombinant IL-8 (hrIL-8) was used to do a migratory assay of fish neutrophils. As shown in Fig. 5C and 5D, hrIL-8 induced remarkable chemotaxis of fish neutrophils but did not affect fish macrophages both in Black Seabream and Common Carp.

\section{Discussion}

The first reported fish chemokine gene from a jawless fish lamprey belonged to the CXC family; the gene encodes an IL-8-like peptide and was called lamprey 'IL-8'. Following these discoveries, similar molecules were identified in different fishes, including shark, trout, flounder and carp [26]. Because their sequences have a high identity with
A

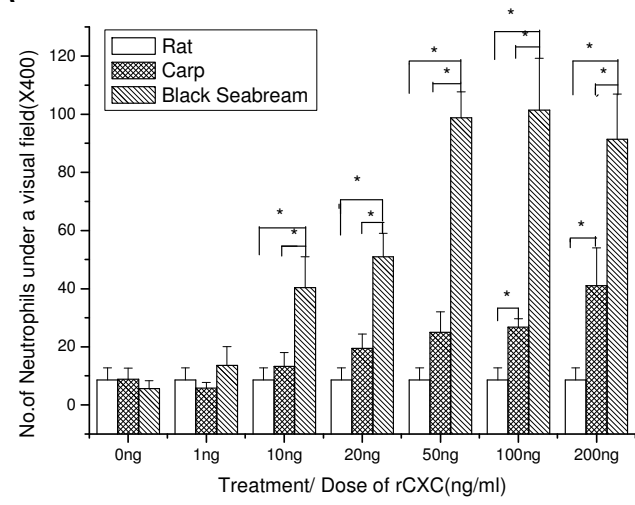

C

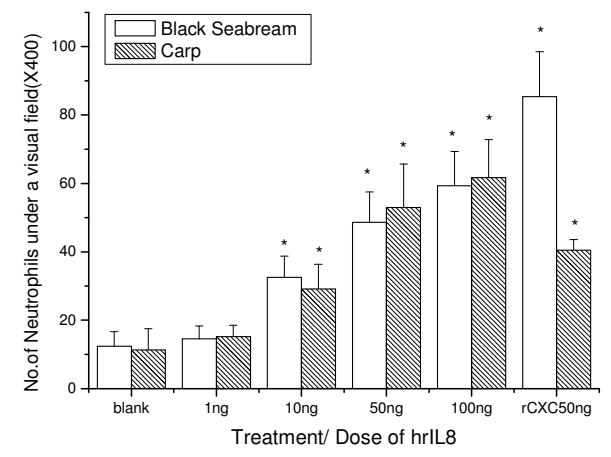

B

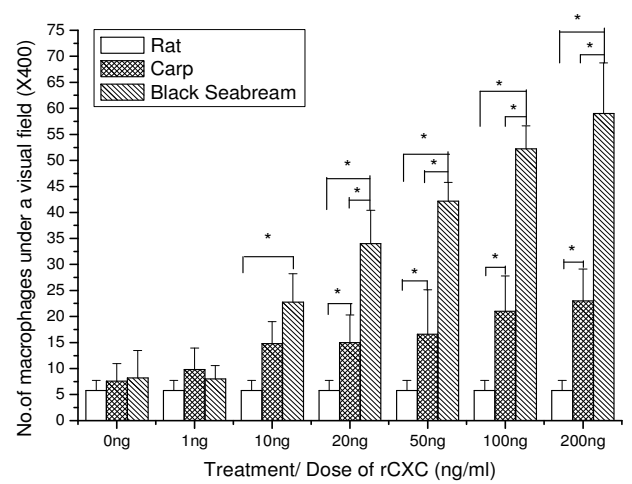

D

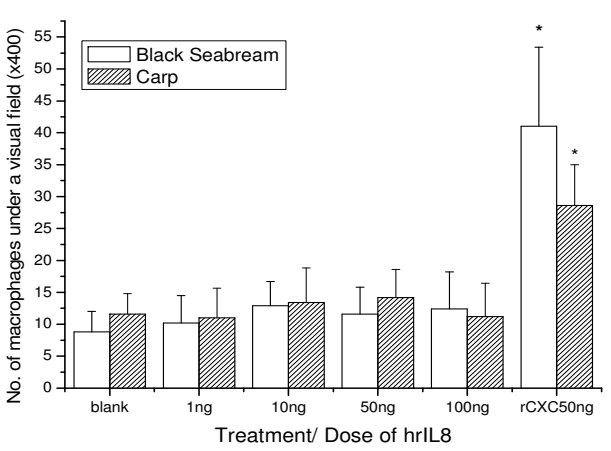

\section{Figure 5}

Migratory assay of leukocytes from different animals towards BS rCXC or human rIL-8. The migration of neutrophilic granulocytes $(A$ and $C$ ) or macrophages $(B$ and $D)$ from black seabream, carp and rat induced by different concentrations of $B S$ rCXC (A and B) or human IL-8 (C and D) was assayed using Transwell.*: $p<0.05$. 
lamprey IL-8, these piscine CXCs were called fish 'IL-8 '; however, the name does not seem suitable, at least in the case of BS CXC.

CXC chemokine ligands are grouped into two subgroups, ELR ${ }^{+}$CXC and ELR-CXC in different species. Mammalian IL- 8 belongs to the ELR ${ }^{+} \mathrm{CXC}$ subgroup of CXC chemokines containing the ELR motif $\left(\mathrm{ELR}^{+}\right)$. This group includes CXCL1 to 8, except CXCL4, and these chemokines have implications in the specificity for granulocytes. In contrast, the ELR- subgroup includes CXCL4 and CXCL9 to 14 , and these chemokines attract lymphocytes and monocytes, with poor chemotactic ability for granulocytes $[5,14,27,28]$. Fish 'IL-8' are grouped into the ELR ${ }^{+}$subgroup but the classification seems unsuitable $[14,29]$, not only because of their incomplete ELR motif, but also because of their functional differences compared with mammalian IL-8.

In this study, we constructed a phylogenetic tree using the neighbour-joining algorithm (Fig. 3) and a similar topology by the maximum-parsimony algorithm (data not shown). Based on our results from phylogenetic analysis and those obtained by others, CXCL12 and CXCL13 are, in phylogenetic terms, modern representatives of the ancestral ELR-CXC chemokine $[7,14]$, and mammalian ELR + CXC and piscine incomplete $\mathrm{ELR}^{+} \mathrm{CXC}$ are derived from ancestral ELR-CXC. Piscine incomplete ELR ${ }^{+} \mathrm{CXC}$ represents an early evolutionary stage of $\mathrm{ELR}^{+} \mathrm{CXC}$. Among the fishes, lamprey 'IL-8' (jawless fishes), which occupies an independent branch, may be the first that evolved from the ELR-CXC ancestor, followed by shark 'IL8' (cartilaginous fish), and finally leading to common carp 'IL-8', rainbow trout 'IL-8', flounder 'IL-8' and BS $\mathrm{CXC}$, etc (bony fishes). Similar to the CXC protein molecules, there is also an evolutionary trend for the fish ELRlike motif, from GGR (jawless fishes) to SLR/SLQ (cartilaginous fish), then to SLH/DLR/ELH (bony fishes), and finally to ELR (birds and mammals). The entire process has probably occurred through multi-time mutations of amino acids that have led to the formation of an ELR motif-a special binding site for the CXC receptor in mammals.

In mammalian species, all CXC chemokines have a similar tertiary structure which contains three $\beta$ strands in the $\mathrm{N}$ terminal and an $\alpha$ helix in the $\mathrm{C}$ terminal, and all the functional CXC chemokines act by binding to G-proteincoupled cell surface receptors via a seven-transmembranedomain, and signaling through a heterotrimeric GTPbinding protein $[9,30]$. Therefore, it is possible that all the CXC chemokines evolved from an ancestral gene through multiple duplication (7). The low identity among CXC genes maybe result in conservative substitutions of amino acids to suitable function-specific diversification in the early evolutionary stages (14).

The differences in molecular structures hint at differences in functions between mammalian IL-8 and fish 'IL-8'. Before this investigation, almost no functional investigations about fish 'IL-8' had been performed, so it was unclear whether fish 'IL-8' and mammalian IL-8 have the same function or not. In this study, we used BS CXC as a model of fish 'IL-8' to investigate the chemotactic functions of fish 'IL-8' and found that BS CXC developed a chemotactic ability for granulocytes, but still kept the chemotactic property of inducing macrophages and neutrophils, compared with its ancestors of the ELR-CXC chemokine. Unlike fish 'IL-8', the mammalian IL-8 evolved a more specialized chemotactic function, inducing only granulocytes, but lost its attraction for macrophages. It is generally acknowledged that the ELR motif is an essential structure for the chemotaxis of granulocytes [25], however, our investigation showed that the incomplete ELR motif of fish 'IL-8', like the ELH of BS CXC, already has chemotactic ability for fish granulocytes, but mammalian IL-8 has a stronger chemotactic ability for granulocytes, not only inducing mammalian granulocytes, but also affecting fish granulocytes. Our results are supported by an experiment on an ELR mutation of human IL-8. When the ELR motif of human IL-8 molecule was mutated to an incomplete ELR motif, such as ALR, EAR or ELA, the mutated human IL-8 retained its neutrophil attracting ability, but also showed a 100 to 1000 fold reduced affinity to bind with neutrophil receptors [25]. These data suggests that the ELR motif is essential for mammalian cells, but in fish incomplete ELR CXC is also functional for the chemotaxis of granulocytes.

Taken together, although fish 'IL-8' with an incomplete ELR motif already has granulocyte-attracting ability similar to mammalian IL-8, it still retains a strong chemotactic ability for monocytes, similar to its ancestor, the ELR-CXC chemokine. It seems that fish incomplete ELR $+C X C$ still retain some properties of the intermediate stage during the evolution from ancient ELR-CXC to ELR ${ }^{+}$CXC chemokines. Therefore, several papers have noted that fish IL-8 is an inappropriate name for piscine chemokines $(14,28)$, and it may be more appropriate to call this molecule 'piscine CXC with an incomplete ELR', instead of terming it fish 'IL-8'.

\section{Conclusion}

A homologue of piscine 'IL-8' from black seabream, called BS CXC, has been cloned and analyzed. The results revealed that $\mathrm{BS}$ CXC has a high gene similarity and tertiary structure similarity with piscine and mammalian CXC chemokines, both ELR ${ }^{+}$CXC and ELR-CXC, although it has a lower identity with ELR-CXC, compared with ELR+CXC 
chemokines. Like other piscine IL-8, BS CXC has only an incomplete ELR motif, which is essential for the mammalian $\mathrm{ELR}^{+} \mathrm{CXC}$ ability to attract granulocytes. Bioactivity assay demonstrated that the BS rCXC significantly stimulated migration of fish neutrophils and macrophages. As an incomplete $\mathrm{ELR}^{+} \mathrm{CXC}$ chemokine from a modern fish, BS CXC provides some clues on the evolution from ancient ELR-CXC to $\mathrm{ELR}^{+} \mathrm{CXC}$ by retaining some properties of the intermediate stage in evolution.

\section{Methods \\ Fish}

Black seabream (Acanthopagrus schlegeli), weighing about $100 \mathrm{~g}$, were collected from a local fish farm in Shenzhen, Guangdong province, and acclimated for 10 days in a 200 $\mathrm{L}$ fiberglass tank containing clean seawater at $25 \pm 3{ }^{\circ} \mathrm{C}$. Each day $25 \%$ of the water was replaced by fresh seawater. Fish were fed commercial food at a daily rate of $1.5 \%$ of their estimated body weight. All the fishes were handled according to the regulations of "U.S. Government Principles for the Utilization and Care of Vertebrate Animals Used in Testing, Research, and Training".

\section{RNA isolation and CDNA synthesis}

Healthy black seabream were challenged with an attenuated marine fish bacterial pathogen of Vibrio anguillarum (about $2 \times 10^{8}$ cells per fish). Then 24 hours after stimulation, the head kidney HK was isolated and homogenized for RNA isolation. Total RNA was extracted by Trizol reagent (Invitrogen, Japan) following the user's manual. The cDNA was synthesized from total RNA by MMLV reverse transcriptase (Promega, USA) with oligo dT or adapter dT primer.

\section{Cloning and sequencing of the CXC homologue}

PCR (polymerase chain reaction) was performed using the CDNA template prepared above and a pair of degenerated primers dCXC-F/dCXC-R (Additional file 1), which were designed based on the conserved regions of the known CXC sequences, to amplify the black seabream CXC (BS CXC) chemokine homologue. The PCR products were ligated into pMD18-T vector (TaKaRa, Dalian) and transformed into XL1-blue E. coli competent cells. Plasmid DNA was isolated using a GenElute plasmid miniprep Kit (Sigma). The insert in the plasmid DNA was sequenced using the ABI377a Automated Sequencer (Applied Biosystems).

Based on the partial sequence of BS CXC, the 5' ends and 3 ' ends were obtained by rapid amplification of cDNA ends (RACE) approaches [31], using gene specific primers and adapter primers (F85/adapter primer; oligo dG/R94) (Additional file 1). The PCR products were cloned to pMD-18T vector and sequenced.
Based on the candidate BS CXC sequence, a pair of primer gF( 5' -ATG ATG AGC AGC AGA GTC- 3')/gR (5'-CAG ATT GTC AGA GCC AGA-3'), which was located in 5'UTR and 3'UTR of the BS CXC sequence, respectively, was designed. RT-PCR was carried out with these primers to get the full length transcript of BS CXC.

\section{Sequence analysis}

The nucleotide sequences were analyzed by the BLAST [32] program to determine gene identities, and multiple sequence alignment was generated using the CLUSTAL W [33] program. The signal peptide prediction was performed by the SignalP program [34] and the protein family signature was identified by the InterPro program [35]. The tertiary structure was predicted by the SWISS-MODEL software [36] and visualized by the Swiss-PdbView software [37]. The phylogenetic tree was constructed based on the full-length amino acid sequences of part of the known mammalian and piscine CXC ligands, using a neighborjoining algorithm within MEGA version 3.1 [38].

\section{Expression studies}

Expression of the BS CXC transcript was studied by fluorescence real-time RT-PCR. Healthy black seabream were challenged with LPS (Sigma) or poly(I:C) (Sigma) at a dose of $3 \mathrm{mg} / \mathrm{kg}$ body weight, and the PBS-challenged fish were used as the negative control. Twenty-four hours after stimulation, total RNA was extracted from different organs, including the gill, heart, head kidney (HK), kidney, spleen and blood. Single-strand cDNA was synthesized with MMLV reverse transcriptase (Promega) and the oligo dT primer (Promega) using DNase I (Promega)treated total RNA as the template. The gene-specific primer F85 and GR primers (Additional file 1) were used to amplify the targets, and the fragment of the $\beta$-actin gene that was amplified by $\beta$-actin-F/ $\beta$-actin-R was used as the internal control to verify quantitative real-time PCR and successful transcription. The fluorescent real-time PCR assay was carried out in an ABI PRISM 7300 Sequence Detection System (Applied Biosystems). The amplifications were performed in triplicates in $20-\mu \mathrm{L}$ reaction volume that contained $10 \mu \mathrm{L} 2 \times$ SYBR Green Master Mix (Applied Biosystems), $1 \mu \mathrm{L}$ (each) forward and reverse primers $\left(10 \mu \mathrm{mol} \mathrm{L}^{-1}\right), 3 \mu \mathrm{L} \mathrm{cDNA}$ and $5 \mu \mathrm{L}$ DEPC-treated water. The thermal program for real-time PCR was $95^{\circ} \mathrm{C}$ for $5 \mathrm{~min}$ followed by 35 cycles at $95^{\circ} \mathrm{C}$ for $30 \mathrm{~s}$ and $61^{\circ} \mathrm{C}$ for $1 \mathrm{~min}$. Dissociation curve analysis of amplification products was performed at the end of each PCR reaction to confirm that only one PCR product was amplified and detected. After the PCR program, fluorescent real-time PCR data from three replicate samples were analyzed with 7300 System SDS Software v.1.4.0 (Applied Biosystems, USA). The comparative CT method was used to analyze the BS CXC expression level. All analyses were based on the CT values of the PCR products. The CT was defined as 
the PCR cycle at which the fluorescence signal crossed a threshold line that was placed in the exponential phase of the amplification curve. The CT for target amplification of BS CXC and that for the internal control $\beta$-actin were determined for each sample. The difference between the CT values of the target and internal control, termed dCT, was calculated to normalize the differences in the amount of total nucleic acid added to each reaction and the efficiency of the RT-PCR. One of the samples was chosen as the reference sample and was called the calibrator. The $\mathrm{dCT}$ for each sample was subtracted from the dCT of the calibrator, and the difference gave the ddCT value. The BS CXC expression level could be calculated by $2^{\text {-ddCT; the }}$ value represented an $\mathrm{n}$-fold difference relative to the calibrator. The data obtained from real-time PCR were subjected to the Student's $t$-test to determine differences in the mean values between the control and treated groups. $P$ values less than 0.01 were regarded as significant.

\section{Construction and expression of recombinant BS CXC}

The cDNA encoding sequences of the deduced mature peptide were amplified by PCR using the gene specific primers $\mathrm{rCXC} \mathrm{F} / \mathrm{rCXC} \mathrm{R}$, which contained restriction enzyme sites for BamHI or Hind III, respectively (Additional file 1). The digested PCR products by Bam HI and Hind III were ligated into expression vector PQE30 (Qiagen) containing a 6 His tag at the $\mathrm{N}$-terminus for purification purposes and cloned into E. coli competent cells M15. The positive clones were screened by PCR with primers pQE30 F/rCXC R and the plasmids of positive clones were purified and sequenced using $\mathrm{pQE} 30-\mathrm{R}$ primer (Additional file 1). The resultant proteins were named BS rCXC.

The positive colony was cultured and induced by IPTG, and then the purified recombinant protein was generated using a Ni-NTA agarose kit (Qiagen) under denaturing conditions, following the user manual. The protein was dialyzed in refolding buffer ( $50 \mathrm{mM}$ PBS containing $1 \mathrm{mM}$ GSH, $0.1 \mathrm{mM}$ GSSH, $1 \mathrm{mg} / \mathrm{ml}$ leupeptin and $1 \mathrm{mg} / \mathrm{ml}$ pepstatin). Expression and purified protein were checked by $4-18 \%$ SDS PAGE gel. Western blot analysis was performed to confirm the identity of the BS rCXC; the monoclonal antibody of 6His (Upstate, USA) was used as the primary antibody for the detection of the Western blot.

\section{Preparation of primary cultured leukocytes}

Head kidney (HK) macrophages and blood neutrophils were isolated according to the method of Solem J (1995) [39] and refined. Briefly, the head kidney of black seabream or common carp was surgically removed, then passed through a 100 um nylon mesh with ice cold L-15 containing $10 \mathrm{U} / \mathrm{mL}$ heparin, $100 \mathrm{ug} / \mathrm{ml}$ penicillin and streptomycin $(\mathrm{P} / \mathrm{S})$. After washing several times, the cells were resuspended in ice cold L-15. The macrophages and blood neutrophils were purified by a discontinuous Per- coll density gradient, collecting more than $80 \%$ of the neutrophils and over $90 \%$ of the macrophages in the purified cells.

Rat blood neutrophils were isolated like fish blood neutrophils isolation, and Rat macrophages were isolated from rat lungs by the perfusion method. Briefly, the lungs and trachea were picked out carefully, HBSS was added from the trachea to wash and perfuse the lung macrophages. The perfusion liquid containing macrophages was sedimented at $400 \times \mathrm{g}$ for $10 \mathrm{~min}$ at $4{ }^{\circ} \mathrm{C}$. The pellet was washed and resuspended with RPMI 1640 medium (containing $15 \mathrm{mmol} / \mathrm{L}$ HEPES, $0.05 \mathrm{U} / \mathrm{ml}$ insulin, $100 \mu \mathrm{g} / \mathrm{ml}$ $\mathrm{P} / \mathrm{S}$ ) supplemented with $5 \%$ fetal calf serum. The viable cells were determined by $0.5 \%$ trypan blue exclusion. All the rats were handled according to the principles of "Public Health Service Policy on Humane Care and Use of Laboratory Animals".

\section{Migration assays}

The migration of the macrophages and the blood neutrophil cells induced by different concentrations of BS rCXC or hrll8 was investigated using Transwell[40] permeable supports (Corning, USA), following the user manual. Briefly, after equilibrium the polycarbonate membrane with a 0.5 um diameter pore was used in the Transwell inserts with a culture medium overnight at $25^{\circ} \mathrm{C}$ or $37^{\circ} \mathrm{C}$, respectively, the BS rCXC or hrIL8 dissolved in fresh L15 culture medium containing 5\% fetal calf serum, $10 \mathrm{U} / \mathrm{mL}$ heparin and $100 \mathrm{ug} / \mathrm{ml} \mathrm{P} / \mathrm{S}$ was added to the plates, then $0.5 \mathrm{ml} 1 \times 10^{6} \mathrm{cell} / \mathrm{ml}$ of the neutrophils or macrophages in fresh medium were added to the Transwell inserts; each dose had three replicates. After $2 \mathrm{~h}$ incubation at $25^{\circ} \mathrm{C}$ or $37^{\circ} \mathrm{C}$ in a humid chamber, the polycarbonate membranes were removed from the insert, and the upper layer cells of the membrane were rinsed with HBSS to remove the cell residues. Then the membranes were fixed in methanol and stained by Giemsa stain and the migration cells passing through the polycarbonate membranes were counted in twenty randomly selected fields under the microscope.

\section{Statistical analysis}

The means and standard errors were calculated from the replicates. The mean values were compared using the Origin 6.0 program (Origin Lab Corporation, USA). A oneway ANOVA test was performed when significant differences occurred at the 5\% level. Differences were considered significant at p-values of $<0.05$.

\section{Authors' contributions}

$\mathrm{CZ}$ Conceived and designed the study and drafted the manuscript. GC, ZY and X K Performed the experiments and analyzed the data. ZYO participated in design of the 
study, helped to draft the manuscript and revised the manuscript.

\section{Additional material}

\section{Additional file 1}

Table for cxc primer

Click here for file

[http://www.biomedcentral.com/content/supplementary/14712172-9-66-S1.doc]

\section{Acknowledgements}

Grant support: This work was supported by Grants (3057/432) from the National Natural Science Foundation, (2006AA 1003 II) from the National $\mathrm{Hi}$-Tech Development Project, (2006CBI01805) from the National Basic Research Program and the Tianjin Basic Research Project (06TXTJJCI4200) of China.

\section{References}

I. Kupper RW, Dewald B, Jakobs KH, Baggiolini M, Gierschik P: G-protein activation by interleukin 8 and related cytokines in human neutrophil plasma membranes. Biochem J 1992, 282(Pt 2):429-34.

2. Campbell Jj, Hedrick J, Zlotnik A, Siani MA, Thompson DA, Butcher EC: Chemokines and the arrest of lymphocytes rolling under flow conditions. Science 1998, 279:38I-4.

3. Strieter RM, Burdick MD, Mestas J, Gomperts B, Keane MP, Belperio JA: Cancer CXC chemokine networks and tumour angiogenesis. Eur J Cancer 2006, 42:768-78.

4. Yoshie O, Imai T, Nomiyama H: Chemokines in immunity. Adv Immunol 200I, 78:57-II0.

5. Laing KJ, Secombes CJ: Chemokines. Dev Comp Immunol 2004, 28:443-60.

6. Zlotnik A, Yoshie O: Chemokines: a new classification system and their role in immunity. Immunity 2000, I 2:121-7.

7. Modi WS, Yoshimura T: Isolation of novel GRO genes and a phylogenetic analysis of the CXC chemokine subfamily in mammals. Mol Biol Evol 1999, 16:180-93.

8. Murphy PM, Baggiolini M, Charo IF, Hebert CA, Horuk R, Matsushima $\mathrm{K}$, Miller LH, Oppenheim JJ, Power CA: International union of pharmacology. XXII. Nomenclature for chemokine receptors. Pharmacol Rev 2000, 52:145-76.

9. Baggiolini M, Dewald B, Moser B: Human chemokines: an update. Annu Rev Immunol I997, I 5:675-705.

10. Bizzarri C, Beccari AR, Bertini R, Cavicchia MR, Giorgini S, Allegretti M: ELR+ CXC chemokines and their receptors (CXC chemokine receptor I and CXC chemokine receptor 2) as new therapeutic targets. Pharmacol Ther 2006, I I 2: I39-49.

II. Najakshin AM, Mechetina LV, Alabyev BY, Taranin AV: Identification of an IL-8 homolog in lamprey (Lampetra fluviatilis): early evolutionary divergence of chemokines. Eur J Immunol 1999, 29:375-82.

12. Laing KJ, Bols N, Secombes CJ: A CXC chemokine sequence isolated from the rainbow trout Oncorhynchus mykiss resembles the closely related interferon-gamma-inducible chemokines CXCL9, CXCLI 0 and CXCLI I. Eur Cytokine Netw 2002, I3:462-73.

13. Fujiki K, Shin DH, Nakao M, Yano T: Molecular cloning of carp (Cyprinus carpio) CC chemokine, CXC chemokine receptors, allograft inflammatory factor-I, and natural killer cell enhancing factor by use of suppression subtractive hybridization. Immunogenetics 1999, 49:909-I4.

14. Huising MO, Stet RJ, Kruiswijk CP, Savelkoul HF, Lidy Verburg-van Kemenade BM: Molecular evolution of CXC chemokines: extant CXC chemokines originate from the CNS. Trends Immunol 2003, 24:307-13.
15. Inoue $\mathrm{Y}$, Endo M, Haruta C, Taniuchi T, Moritomo T, Nakanishi T: Molecular cloning and sequencing of the silver chimaera (Chimaera phantasma) interleukin-8 cDNA. Fish Shellfish Immunol 2003, 1 5:269-74.

16. Inoue Y, Haruta C, Usui K, Moritomo T, Nakanishi T: Molecular cloning and sequencing of the banded dogfish (Triakis scyllia) interleukin-8 cDNA. Fish Shellfish Immunol 2003, 14:275-8I.

17. Lee EY, Park HH, Kim YT, Choi TJ: Cloning and sequence analysis of the interleukin-8 gene from flounder (Paralichthys olivaceous). Gene 200I, 274:237-43.

18. Noubissi FK, Elcheva I, Bhatia N, Shakoori A, Ougolkov A, Liu J, Minamoto T, Ross J, Fuchs SY, Spiegelman VS: CRD-BP mediates stabilization of betaTrCPI and c-myc mRNA in response to beta-catenin signalling. Nature 2006, 441:898-90I.

19. Baoprasertkul P, Peatman E, Chen L, He C, Kucuktas H, Li P, Simmons $M$, Liu Z: Sequence analysis and expression of a CXC chemokine in resistant and susceptible catfish after infection of Edwardsiella ictaluri. Dev Comp Immunol 2004, 28:769-80.

20. Oppenheim JJ, Zachariae CO, Mukaida N, Matsushima K: Properties of the novel proinflammatory supergene "intercrine" cytokine family. Annu Rev Immunol 1991, 9:617-48.

21. Baldwin ET, Franklin KA, Appella E, Yamada M, Matsushima K, Wlodawer A, Weber IT: Crystallization of human interleukin-8. A protein chemotactic for neutrophils and T-lymphocytes. J Biol Chem 1990, 265:685I-3.

22. Rajarathnam K, Clark-Lewis I, Sykes BD: I H NMR solution structure of an active monomeric interleukin-8. Biochemistry 1995, 34: $12983-90$.

23. Montserret R, McLeish MJ, Bockmann A, Geourjon C, Penin F: Involvement of electrostatic interactions in the mechanism of peptide folding induced by sodium dodecyl sulfate binding. Biochemistry 2000, 39:8362-73.

24. Dealwis C, Fernandez EJ, Thompson DA, Simon RJ, Siani MA, Lolis E: Crystal structure of chemically synthesized [N33A] stromal cell-derived factor Ialpha, a potent ligand for the HIV-I "fusin" coreceptor. Proc Natl Acad Sci USA 1998, 95:694I-6.

25. Hebert CA, Vitangcol RV, Baker JB: Scanning mutagenesis of interleukin-8 identifies a cluster of residues required for receptor binding. J Biol Chem I991, 266: 18989-94.

26. Chen L, He C, Baoprasertkul P, Xu P, Li P, Serapion J, Waldbieser G, Wolters W, Liu Z: Analysis of a catfish gene resembling interleukin-8: cDNA cloning, gene structure, and expression after infection with Edwardsiella ictaluri. Dev Comp Immunol 2005, 29:135-42.

27. Fernandez PC, Frank SR, Wang L, Schroeder M, Liu S, Greene J, Cocito A, Amati B: Genomic targets of the human c-Myc protein. Genes Dev 2003, 17:1 I1 15-29.

28. Geiser T, Dewald B, Ehrengruber MU, Clark-Lewis I, Baggiolini M: The interleukin-8-related chemotactic cytokines GRO alpha, GRO beta, and GRO gamma activate human neutrophil and basophil leukocytes. J Biol Chem 1993, 268:15419-24.

29. Wiens GD, Glenney GW, Lapatra SE, Welch TJ: Identification of novel rainbow trout (Onchorynchus mykiss) chemokines, CXCdI and CXCd2: mRNA expression after Yersinia ruckeri vaccination and challenge. Immunogenetics 2006, 58:308-23.

30. Lee J, Cacalano G, Camerato T, Toy K, Moore MW, Wood WI: Chemokine binding and activities mediated by the mouse IL8 receptor. J Immunol 1995, 155:2158-64.

31. Frohman MA: Rapid amplification of complementary DNA ends for generation of full-length complementary DNAs: thermal RACE. Methods Enzymol 1993, 21 8:340-56.

32. Altschul SF, Gish W, Miller W, Myers EW, Lipman DJ: Basic local alignment search tool. J Mol Biol 1990, 215:403-10.

33. Thompson JD, Higgins DG, Gibson TJ: CLUSTAL W: improving the sensitivity of progressive multiple sequence alignment through sequence weighting, position-specific gap penalties and weight matrix choice. Nucleic Acids Res 1994, 22:4673-80.

34. Nielsen H, Engelbrecht J, Brunak S, von Heijne G: Identification of prokaryotic and eukaryotic signal peptides and prediction of their cleavage sites. Protein Eng 1997, 10:1-6.

35. Apweiler R, Attwood TK, Bairoch A, Bateman A, Birney E, Biswas M, Bucher P, Cerutti L, Corpet F, Croning MD, et al: The InterPro database, an integrated documentation resource for protein families, domains and functional sites. Nucleic Acids Res 200I, 29:37-40. 
36. Schwede T, Kopp J, Guex N, Peitsch MC: SWISS-MODEL: An automated protein homology-modeling server. Nucleic Acids Res 2003, 31:3381-5.

37. Guex N, Peitsch MC: SWISS-MODEL and the Swiss-PdbViewer: an environment for comparative protein modeling. Electrophoresis 1997, 18:27|4-23.

38. Kumar S, Tamura K, Nei M: MEGA3: Integrated software for Molecular Evolutionary Genetics Analysis and sequence alignment. Brief Bioinform 2004, 5: I50-63.

39. Solem STJJB, Robertsen B: Stimulation of respiratory burst and phagocytic activity in Atlantic salmon (Salmo salar L.) macrophages by lipopolysaccharide. Fish Shellfish Immunol 1995, 5:475-491.

40. Falk W, Goodwin RH Jr, Leonard Ej: A 48-well micro chemotaxis assembly for rapid and accurate measurement of leukocyte migration. J Immunol Methods 1980, 33:239-47.

Publish with Bio Med Central and every scientist can read your work free of charge

"BioMed Central will be the most significant development for disseminating the results of biomedical research in our lifetime. "

Sir Paul Nurse, Cancer Research UK

Your research papers will be:

- available free of charge to the entire biomedical community

- peer reviewed and published immediately upon acceptance

- cited in PubMed and archived on PubMed Central

- yours - you keep the copyright

Submit your manuscript here:

http://www.biomedcentral.com/info/publishing_adv.asp
BiolMedcentral 